RIPS, ISSN 1577-239X. Vol. 7, núm. 2, 2008, 9-23

\title{
LAS AMBIVALENCIAS DE LA DEMOCRACIA CONTEMPORÁNEA EN UN MUNDO INSOPORTABLEMENTE COMPLEJO E INSOLIDARIO
}

\author{
H.C.F. Mansilla \\ Academia Boliviana de Ciencias
}

\begin{abstract}
Resumen: Un proceso de desarrollo centrado en aspectos técnico-económicos, la dilatada corrupción y el mal desempeño administrativo han desacreditado la democracia liberal pluralista en numerosos países del Tercer Mundo. La modernización parcial no ha tocado las propias tradiciones autoritarias. Por otra parte, el renacimiento del comunitarismo tiene que ver con el hecho de que el neoliberalismo ha devaluado los aspectos de solidaridad, confianza e identidad colectiva, que aun tenía el mundo premoderno. Pese a todo, la democracia pluralista aparece como el mal menor, dentro de una posible síntesis entre comunitarismo y liberalismo, universalismo y particularismo.

Palabras clave: Comunitarismo, democracia moderna, desilusión, Jürgen Habermas, liberalismo.

Abstract: A mostly ecomomic-technical development, the spread of corruption and the poor administrative performance have depreciated the liberal pluralistic democracy in many Third World countries. A partial modernization process has not affected the own authoritarian traditions. On the other side, the renaissance of communitarism must be seen with the fact that neoliberalism has depreciated the aspects of solidarity, trust and identity, which were proper to the premodern world. Despite all, pluralistic democracy emerges as the lesser evil within a possible synthesis of communitarism and liberalism, universalism and particularism.
\end{abstract}

Key words: Communitarism, disappointment, Jürgen Habermas, liberalism, modern democracy.

PRELIMINARES: LA DESILUSIÓN CON EL NEOLIBERALISMO

Anticipando las conclusiones se puede aseverar lo siguiente. Un esfuerzo didáctico (desde una perspectiva filosófica, no politológica) y una evaluación sobria de los modelos político-institucionales contemporáneos -que eviten los extremos interpretativos sin declinar en la intención crítica -nos llevan en primer término a conocer los aspectos negativos de los diversos sistemas, las limitaciones de las democracias contemporáneas y hasta las carencias intrínsecas de los designios mejor encaminados para asegurar la convivencia razonable de los mortales. Un bon mot atribuido a Sir Winston S. Churchill 
afirma que la moderna democracia pluralista es un régimen mediocre, pero que todos los otros son aun peores. Este punto de vista realista (a) nos recuerda en primer término las características negativas de la democracia, que no pueden y no deben ser pasadas por alto, pero también (b) nos ayuda a reconocer sus bondades, sobre todo si realizamos un análisis comparativo con otros sistemas de ordenamiento social en un amplio contexto supranacional' ${ }^{1}$. La democracia moderna resulta el mal menor, si percibimos que el mundo actual alberga numerosos modelos autoritarios, gobiernos autocráticos, experimentos populistas y regímenes tradicionalistas, todos ellos plenos de elementos irracionales. Este último calificativo está elegido premeditadamente, pues no podemos caer en la cómoda posición relativista que postula la incomparabilidad de los paradigmas humanos de estructuración política, lo que significa, por ejemplo, una indulgencia muy generosa para con fenómenos autoritarios, sólo porque estos últimos pertenecerían a tradiciones culturales distintas de las de Europa Occidental.

Como conclusión adicional se puede decir que los regímenes democráticos vinculados al neoliberalismo económico y cultural han resultado una desilusión en gran parte del Tercer Mundo, un desencanto de magnitud considerable y con implicaciones políticas de gran repercusión. $Y$ hay que ver esta decepción dentro de un contexto mundial consagrado a intentos estrictamente racionales y modernizantes por mejorar el marco político, social y económico de las naciones del Tercer Mundo, contexto conformado por las instituciones supranacionales más importantes y por el quehacer de los especialistas más destacados en ciencias sociales. La desilusión resulta comprensible en su dimensión e intensidad puesto que estos modelos -a partir de más o menos 1980 -fueron concebidos, justificados y publicitados como la superación de las falencias premodernas y como la expresión más notable de políticas públicas científicamente elaboradas.

Por otra parte no han faltado notables logros en los procesos de modernización de las últimas décadas. Se han expandido, sin duda alguna, los subsistemas de educación moderna, deliberación democrática y participación popular; a comienzos del siglo XXI América Latina, Asia y Africa constituyen sociedades muy diferentes de sus predecesoras en un lapso de tiempo de escasos cincuenta años, pero falta afianzar estos factores de manera consistente y crear una atmósfera amplia de confianza institucional. Esta carencia ha sido decisiva para que a comienzos del siglo XXI la opinión pública perciba más clara y dolorosamente uno de los problemas mayores del neoliberalismo tercermundista: la conjunción de corrupción con ineptitud.

Un factor ético con vinculaciones económicas (la corrupción de magnitud insospechada) y uno técnico con nexos institucionales (la ineptitud manifiesta en la administración pública) han devaluado al neoliberalismo en los ojos de la opinión pública y de los votantes. En América Latina, salvo Chile y Costa Rica, se expande un marcado desencanto con la teoría y la praxis neoliberales. La expresión "neoliberal" está vinculada a varios aspectos. En las últimas décadas las ideas neoliberales se han impuesto en gran parte del mundo, sobre todo en la reorganización de la economía y las finanzas públicas y en el redimensionamiento del rol del Estado, pero, simultáneamente, los partidos liberales "clásicos" tienden a desaparecer, favoreciendo agrupaciones conservadoras, populistas, nacionalistas y regionalistas. En contraposición al liberalismo de épocas pasadas, el neoliberalismo del presente y del Tercer Mundo está caracterizado por la dilución de los viejos principios liberales iusnaturalistas. A esto corresponde, en el plano cultural y en la esfera específicamente política, un agotamiento del liberalismo en cuanto proyecto movilizador para 
el futuro y creador de instituciones y valores de orientación de amplio alcance.

Este agotamiento puede ser aclarado recapitulando parcialmente el debate entre comunitarismo y liberalismo. Aunque en los últimos años las teorías comunitaristas gozan del favor creciente del público académico, sobre todo en el Tercer Mundo, no hay duda de que su potencial explicativo ha sido sobreestimado en gran escala; al mismo tiempo, en el plano político de la realidad cotidiana, la opinión pública en Asia, África y América Latina percibe ahora las deficiencias de los regímenes neoliberales de modo exagerado, cuando no injusto. El renacimiento del comunitarismo tiene que ver con el hecho de que el neoliberalismo ha devaluado aun más los aspectos de solidaridad, confianza e identidad colectiva ${ }^{2}$ que florecen presuntamente en el orden premoderno y comunitario, aspectos que han sido debilitados o aniquilados por la modernización acelerada de las últimas décadas.

La nostalgia por un sistema social que brinde solidaridad en sus muchas facetas ${ }^{3}$ es uno de los factores que subyace al renacimiento de prácticas religiosas. Este fenómeno no se da exclusivamente en el ámbito islámico, sino que alcanza los más variados territorios culturales. El análisis de los presupuestos prepolíticos de la democracia (o dicho de manera más provocativa: los cimientos en parte religiosos de la convivencia razonable de los mortales) ha pasado a ser una materia importante de estudio de la filosofía y sociología políticas. La Escuela de Frankfurt, que a menudo ha producido intuiciones clarividentes sobre temas religiosos, se ha preocupado últimamente por esos fundamentos premodernos de la democracia, que a priori no deben ser calificados de irracionales. EI ordenamiento social basado en el racionalismo y configurado por la modernidad ha generado, como se sabe de forma exhaustiva, severas pérdidas en los campos afectivo, familiar, laboral e institucional, lo que, a su vez, ha motivado un renovado interés por aquellos modelos civilizatorios que aparentemente originaban un prácticas generalizadas de solidaridad no mediada burocráticamente. Y ellos combinaban una religiosidad tomada en serio con manifestaciones de solidaridad y con una concepción aun intacta sobre el sentido de la historia y la existencia. Todo esto ha complicado paradójicamente la dimensión política de la actualidad y su tratamiento teórico.

\section{LA NECESIDAD DE LA CRÍTICA A LA DEMO- CRACIA COMO MECANISMO MERCANTIL}

Siguiendo un teorema de Max Weber y de la Escuela de Frankfurt, que ha demostrado ser clarividente, se puede sostener que el orden social actual en amplias regiones del Tercer Mundo se encuentra sometido a la dictadura de una racionalidad básicamente instrumental. Sus criterios de legitimización han cesado de ser la libertad y la autonomía individuales y la autodeterminación democrática, dando paso a valores rectores como el desempeño económico-financiero, el éxito material y el consumo grosero. El éxito inmenso de la tecnología y su penetración en casi todas las esferas de la vida moderna han conducido a atribuir a la racionalidad instrumental y a sus manifestaciones socio-políticas un aura de verdad inconmovible, ante la cual el debate clásico en torno a ideas y programas, por una parte, y la concurrencia libre de los partidos por el favor de los electores, por otra, adoptan el aire de un penoso anacronismo. El carácter científico-técnico de los asuntos centrales de nuestra civilización hace muy difícil su crítica por parte de gente que no tiene los conocimientos especializados pertinentes. La tecnificación y la cientifización del mundo transforman la democracia liberal en algo obsoleto.

No hay duda de que los sistemas neoliberales del presente poseen algunos factores positivos: un alto grado de movilidad social y personal, una notable diferenciación de roles y funciones y unas posibili- 
dades bastante amplias en la elección de comportamientos y valores. Pero estas sociedades de cuño neoliberal Ilevan asimismo a la atomización de los ciudadanos, a la obsolescencia de la discusión pública intelectual, a la competencia brutal por cualquier nimiedad y a la anomia como factor influyente de la praxis colectiva. La decepción mencionada tiene que ver con el hecho fundamental de que hoy en día la actividad política ha sido degradada y convertida en una función del mercado omnipotente, en el cual los medios masivos de comunicación juegan un papel predominante. También en América Latina se puede constatar la popular idea de que la política en su forma tradicional puede dejar de existir y transformarse en una asignación de recursos por medio del mercado. Se disuelve la posibilidad de control democrático de políticas públicas, ya que estas pasan a la tuición de organismos supranacionales que generalmente no están conformados por una elección democrática. Según Jürgen Habermas, esta "constelación postnacional" puede conducir a que la política se convierta en una gestión tecnocrática, sin gozar de la necesaria legitimidad democrática. Esta es la tendencia aparentemente universal a la economización de la política. El poder se reduce al dinero. El poder puede ser democratizado, dice Habermas, el dinero $\mathrm{no}^{4}$. La regulación de decisiones opera como la lógica de opciones mercantiles, para la cual criterios como el bien común ${ }^{5}$, la experiencia histórica o el sopesar riesgos sociales, simplemente no existen.

Por todo ello y a la vista del desencanto generado por el neoliberalismo, sobre todo en América Latina, se expande en círculos académicos la necesidad de un análisis exhaustivo de la llamada democracia neoliberal. Adelantándose a los cientistas políticos, un gran liberal, como lo fue Octavio Paz, lo dijo clara y concisamente: hay que poner en duda la ideología del mercado qua nueva religión obligatoria. "EI mercado es el promotor de los cambios y las innovaciones técnicas; también es el rey del despilfarro. [...] A nosotros el mercado nos condena a desechar lo que compramos ayer $y$, por la boca ubicua de la publicidad, nos intoxica con la droga infernal de la novedad. Idolatría del siglo XX: la adoración de las cosas nuevas que duran lo que dura un parpadeo" 6 . En lugar de producir pocos artículos, pero de gran calidad y durabilidad, el mercado nos inunda con cosas de baja calidad y poca duración, pero que son vistosas y parecen irresistibles. El mercado constituye un procedimiento inigualado en su precisión y eficacia para detectar carencias, descubrir los deseos de los consumidores y asignar recursos escasos, pero también es imparable a la hora de agotar los recursos naturales, destruir los ecosistemas, generar montañas de basura, homogeneizar las sociedades a lo ancho y lo largo del planeta y domeñar a los seres humanos.

Por otra parte no es conveniente en absoluto abolir el mercado y el comercio libres, máxime si los experimentos socialistas, que se dedicaron a este objetivo hasta 1989, fracasaron estrepitosamente en la persecución de este fin y sembraron más problemas que soluciones. El mercado y el comercio libres han resultado ser indispensables: son el motor del desarrollo y del intercambio entre las naciones y las culturas. Sin ellos el mundo sería infinitamente más pobre... y más aburrido. Hay que considerar, sin embargo, lo que añadió Octavio Paz: "Pero el mercado no es una ley natural ni divina: es un mecanismo inventado por los hombres. Como todos los mecanismos es ciego: no sabe a dónde va, su misión es girar sin fin"7. Por lo tanto, no hay que abolirlo ni restringirlo, pero sí humanizarlo, aunque la concreción de este postulado en la praxis cotidiana es algo inmensamente difícil.

La crítica del mercado debe ser complementada por una de los medios masivos de comunicación, sobre todo en vista de la relevancia extraordinaria que éstos han adquirido en las últimas décadas. La 
enorme cantidad de literatura publicada ${ }^{8}$ sobre esta temática nos exime de entrar en detalles o de intentar una especie de síntesis, reproduciendo en cambio unos pensamientos de Octavio Paz. Los puntos principales de esta crítica son la baja calidad cultural de lo que irradian los medios, la cultura del conformismo que propagan y el consumismo desbocado que impulsan. Octavio Paz señaló la tediosa similitud de imágenes y fórmulas que los medios emiten sin pausa: "La civilización de la libertad nos ha convertido en una manada de borregos. [...] Uno de los rasgos en verdad desoladores de nuestra sociedad es la uniformidad de las conciencias, los gustos y las ideas, unida al culto de un individualismo egoísta y desenfrenado" 9 . El elevado nivel civilizatorio del presente ha producido también una satisfacción de las masas que se destaca sólo por su carácter apolítico, superficial y cambiante. Justamente en relación con la política, los medios han introducido en esta esfera una cultura del entretenimiento sin escapatoria, vaciando de todo contenido serio a la discusión ideológica y a la elección de alternativas programáticas. Los medios y especialmente la televisión han transformado la libertad de expresión -una conquista irrenunciable de la humanidad -en un "instrumento de domesticación intelectual, moral y política"10. El resultado global fue descrito así por Octavio Paz: "El mercado ha minado todas las antiguas creencias -muchas de ellas, lo acepto, nefastas -pero en su lugar no ha instalado sino una pasión: la de comprar cosas y consumir este o aquel objeto. Nuestro hedonismo no es una filosofía del placer sino una abdicación del albedrío [...]. El hedonismo no es el pecado de las democracias modernas: su pecado es su conformismo, la vulgaridad de sus pasiones, la uniformidad de sus gustos, ideas y convicciones" 11 .

A esto hay poco que agregar, sobre todo si consideramos otros aspectos negativos asociados a la moderna democracia de masas. En un amplio estudio sobre
Nigeria, la mayor democracia africana (en términos numéricos de población), se llega a la conclusión paradójica de que la democracia contemporánea, basada en el derecho universal de voto, fomenta la expansión de grandes masas de partidarios ocasionales, para los cuales el aliciente mayor es de carácter material, como un empleo o una gratificación, por más pequeña que esta sea ${ }^{12}$. En muchísimas sociedades se puede detectar un fenómeno similar. Para ganar una elección en un sistema libre y competitivo dentro del marco de las democracias actuales con millones de votantes, es imprescindible contar con dilatados grupos de simpatizantes. Para conformar estas masas y mantenerlas contentas, hay que acudir a procedimientos modernizados de comportamientos tradicionales, como el favoritismo, el prebendalismo y el patrimonialismo, que no son un dechado de virtudes democráticas. La lucha por el poder, que constituye el núcleo de la política, se transforma en mecanismos "eficientes" para conseguir, por lo menos parcialmente, la preferencia de los votantes, y ello es imposible hoy en día sin satisfacer algunos de los anhelos de la población referidos a un mejor nivel de vida y a distracciones de acuerdo a las modas del momento. Como escribió Mario Vargas Llosa, "las contiendas electorales se deciden cada vez más en función de la publicidad y cada vez menos debido a los programas y razones que proponen los candidatos"13. En esta constelación no es sorprendente que cantantes, presentadores de televisión y actores lleguen a ser políticos de primer nivel.

En conclusión: el peligro inherente a la modernización parcial, como se da en la mayoría de las naciones del Tercer Mundo, consiste en la construcción de una sociedad urbana e industrializada, pero sin un fundamento humanista y sin una firme cultura democrática, pluralista y laica. Según las circunstancias históricas, esta sociedad puede impedir el aprendizaje de un entendimiento comunicativo de amplio alcance 
y desarrollar una afinidad para con modelos autoritarios y hasta totalitarios.

\section{DEFICIENCIAS DE LA DEMOCRACIA CONTEMPORÁNEA}

No sólo el actual relativismo de valores, sino también un elemento intrínseco de la democracia nos lleva a dudar de su bondad global, y es algo que fue tematizado ampliamente desde pensadores clásicos como Aristóteles y Tucídides. Hay que considerar al mismo tiempo que el estudio de la historia y de experiencias concretas no siempre nos puede enseñar algo: nuestros esfuerzos teóricos más notables pueden rendir frutos muy modestos ${ }^{14}$.

La crítica del mercado y de los medios quedaría inconclusa sin un cuestionamiento de la democracia moderna, por más somero que este sea. Como se sabe, el muy complejo edificio de la democracia actual se construyó sobre cimientos que provienen de la Grecia clásica y que fueron enriquecidos por aportes de diferentes épocas y culturas. El respeto a la voluntad de la mayoría es complementado por la protección de los derechos de las minorías y, encima de todo, por el Estado de Derecho. Este sistema, cuya calidad y eficiencia están avaladas por un largo desarrollo histórico y por su expansión a nivel mundial durante el siglo XX, no puede, sin embargo, responder preguntas esenciales de los ciudadanos, como aquellas sobre el sentido de la vida, la dirección de la evolución a largo plazo y la consecución de la felicidad individual.

Esta última cuestión no es una simple nostalgia infantil. Desde Aristóteles se concibe la política como algo más que un lugar de maximización de preferencias sociales, porque estas preferencias tienen que ver con valores éticos y con asuntos relativos a la justicia. La participación política, por lo tanto, no puede ser asimilada (o reducida) a un modelo de mercado, sino que se parece más a un foro público, donde la par- ticipación libre de los ciudadanos es equivalente a su autorrealización: un fin en sí mismo ${ }^{15}$. (No es superfluo recordar que el concepto de democracia como fin en sí mismo es controvertido.) La participación política no puede ser identificada con una mera forma de actividad mercantil, pues casi todo intento en este sentido implica nolens volens la búsqueda del bien común $y$, por ende, la superación de las formas más groseras del egoísmo individualista, aunque esto ocurra mayoritariamente en el plano teórico.

Los dos elementos fundantes de la democracia son: (a) la suposición de que los ciudadanos son capaces de decidir adecuadamente acerca de los asuntos públicos y (b) que las decisiones son tomadas con libertad individual y responsabilidad cívica. Frente a estos supuestos teóricos se halla la realidad empírica del presente. No sólo está el problema contemporáneo de la creciente complejidad y complicación de esos asuntos públicos, sino también la posibilidad real de la manipulación de consciencias por los demagogos, los medios de comunicación y los sistemas educacionales. El ser humano es proclive al error y al engaño, lo que se detectó claramente desde tiempos inmemoriales en la esfera política. La posibilidad de informarse adecuadamente, el análisis de los propios intereses y el debate libre, previos a las elecciones y a la toma de decisiones, parecerían configurar el antídoto contra estos males, pero la historia de la democracia nos muestra precisamente que éste no es siempre el caso. En el presente el debate libre -que jamás garantizó la sabiduría de los políticos y nunca evitó la credulidad del público -se ha transformado en un espectáculo mediático, normado por las leyes de la audiencia, limitado por la fugacidad del tiempo en la televisión e influido por las necesidades del circo. Nos queda sólo un modesto consuelo: la vigencia de la libertad de expresión puede contribuir a mitigar las estulticias propias de los humanos y a reducir el margen de error. 
De acuerdo a Habermas, bajo el liberalismo postmoderno el sistema de libertades públicas e individuales tiende a transformarse en derechos individualistas, subjetivos y posesivos, que adoptan un carácter instrumentalista, consagrados a defender sólo intereses particulares y motivos utilitaristas. Por ello se puede aseverar que a los actuales regímenes basados en el liberalismo económico les falta el ámbito de la solidaridad. Sin esta última no puede prosperar la dimensión de los derechos políticos, ya que la utilización de derechos (también en la constelación de la autonomía privada) presupone una determinada orientación hacia el bien común: las normas, las leyes y las regulaciones generales derivan su legitimidad del hecho de que podrían haber sido postuladas o anheladas por todos ${ }^{16}$.

\section{LOS PRESUPUESTOS PREPOLÍTICOS DE LA DEMOCRACIA Y SUS IMPLICACIONES}

En la fundamentación de las bondades de la democracia moderna Jürgen Habermas oscila entre dos suposiciones centrales.

(A) Por un lado afirma que el proceso democrático poseería por sí mismo un desempeño racional. Su status (histórico y práctico) superior en comparación con otros modelos de institucionalidad política se derivaría de su propia calidad procedimental, de su capacidad para la formación libre y espontánea de voluntades y opiniones políticas, a lo que contribuirían la institucionalización jurídica del proceso de formación de opiniones y la vigencia de los derechos humanos. La fundamentación de este tipo de democracia sería autorreferencial y no requeriría de elementos prepolíticos de otros orígenes o influencias.

(B) Por otro lado están sus análisis sobre la influencia positiva de los factores culturales prepolíticos, sobre todo la influencia de las religiones. Como se sabe por los avances de la antropología y la historia de las ideas, el pensamiento científico y el re- ligioso provienen de una fuente común ${ }^{17}$. La formación de concepciones filosóficas ha estado, a lo largo de milenios, influida por inspiraciones religiosas y teológicas, lo que, según Jürgen Habermas, afecta también e inevitablemente el contenido mismo de las teorías ${ }^{18}$. De acuerdo a Habermas, hasta el pensamiento postmetafísico del presente sólo puede ser entendido adecuadamente si se incluye en su propia genealogía a la metafísica y las grandes tradiciones religiosas. Sería irracional el desechar este legado como un resto arcaico sin importancia. Con alguna reserva Habermas llamó la atención sobre los fundamentos prepolíticos del Estado de Derecho ${ }^{19}$, los cuales provienen de las grandes religiones, del pensamiento profético y de la reflexión teológica. Las concepciones clásicas de autonomía, individualidad, emancipación, justicia social y solidaridad son impensables sin el aporte de los credos judío y cristiano. Hasta hoy las religiones articulan "una consciencia de lo que falta" ${ }^{20}$. Es decir: mantienen despierta una sensibilidad hacia fallos y carencias y, para nombrar un ejemplo actual, preservan del olvido la memoria de la destrucción causada por el progreso racional. Las religiones expresan intuiciones morales acerca de nuestras formas de convivencia y nuestras soluciones políticas. Y, sobre todo, contribuyen a vincular las reglas frías y abstractas de la moral universalista con imágenes de un mundo mejor, es decir con nociones de felicidad y paz.

La solución no sería, entonces, un cristianismo helenizado (la razón proviene de Grecia y la fe de Jerusalem), porque esta alternativa amputaría lo racional del cristianismo primigenio, que es resistirse al olvido del sufrimiento pasado. Su rasgo utópico es la posibilidad de vivir sin miedo. Esta razón recordatoria o anamnética ${ }^{21}$ no está contrapuesta al núcleo de la llustración, pues se basa en poder experimentar el sentimiento de culpa y responsabilidad, que es la precondición de la libertad individual. La razón anamnética es partidaria de 
mantener viva la memoria de las discontinuidades históricas y los quebrantamientos individuales -el sufrimiento en general -y es, por lo tanto, adversa a la fuerza normativa de la facticidad, la costumbre y el olvido y a los sistemas conexos de legitimizar la realidad por ser la única realidad existente. Según Habermas, estos fragmentos de origen judío y cristiano -sentimientos y valoraciones morales de inspiración religiosa -han posibilitado, a veces por vía indirecta, elementos fundamentales de la tradición racional-democrática y la constitución de una razón comunicativa. Entre ellos se encuentran la concepción de la libertad subjetiva, la demanda de un respeto igual para todos, el reconocimiento recíproco (derivado de la autorrestricción de la voluntad por consideraciones éticas), la pertenencia de los individuos a comunidades que brindan solidaridad práctica y la consciencia de la falibilidad del espíritu humano en medio de la contingencia de las condiciones históricas, sin dejar caer por ello las pretensiones morales ${ }^{22}$.

Es imprescindible mencionar, aunque de manera muy somera, algunos análisis del enfoque habermasiano provenientes de América Latina. Los más interesantes están centrados en el renacimiento de la concepción convencional de la democracia directa y se nutren de la tradición populista revolucionaria, adversa, en el fondo, a la democracia representativa liberal y pluralista. El Ilamado patriotismo constitucional, que el filósofo alemán ha propugnado en las últimas décadas, no es suficiente, dicen los críticos. La celebrada autorreferencialidad de la democracia moderna -en cuanto autosuficiencia histórica, creativa y propositiva -no satisface a nadie: sería un reduccionismo institucionalista, no lejos de algunos pensadores postmodernistas y contractualistas dogmáticos. Y representaría una renuncia a una definición de contenido de la democracia y de la soberanía populares. Las "decisiones" del pueblo soberano, que se comprende y se interpreta a sí mismo, pueden y deben sobrepasar, modificar y hasta anular los procedimientos "formales" de la democracia moderna. Numerosos autores han señalado que el ciudadano de la democracia neoliberal del presente -y del modelo habermasiano -puede ser visto paradójicamente como un consumidor de bienes políticos (contra la convicción íntima de Habermas), que por ello estaría excluido de los verdaderos circuitos de decisión (que permanecerían altamente elitarios y cerrados). Por todo ello este tipo de ciudadanía podría ser calificado de incompleto. Lo que necesitaría la sociedad contemporánea, sobrepasando y superando el modelo habermasiano, sería una reconstrucción del espacio democrático y una regeneración del espacio público ${ }^{23}$. Este renovado interés por la democracia directa conlleva asimismo una consideración muy positiva de los aspectos prepolíticos y premodernos de la democracia, sobre todo los referidos a la tradición latinoamericana del populismo y fenómenos conexos.

Estos análisis reproducen la crítica izquierdista convencional dirigida al núcleo de la democracia moderna. Insistiendo en la "crisis de representatividad", que afectaría a esta última, propugnan entonces recuperar la figura del pueblo soberano - presuntamente soslayada por la tradición liberal -mediante mecanismos de mayor participación directa (referéndum, plebiscito, consulta popular, derogatoria de mandato, iniciativa legislativa ciudadana), que resultarían fácilmente comprensibles para la población. Estos argumentos pasan rápidamente por alto la experiencia histórica, repetida muchas veces también en países latinoamericanos, de la posibilidad de manipulación de dilatados sectores populares por medio de plebiscitos y otros instrumentos de "democracia directa". Los casos de Venezuela, Ecuador y Bolivia en los primeros años del siglo XXI son elocuentes. Los valores normativos que se hallan detrás de estos postulados pertenecen a una visión acrítica y utopista de la democracia, aunque estén expresados mediante enfoques 
exitosos mediáticamente, que combinan a menudo un psicoanálisis simplificado, un postmodernismo a la moda del día y el elogio del conflicto ${ }^{24}$. Entre estos valores se hallan la exaltación de la acción colectiva, la democracia como práctica real y cotidiana de la igualdad ${ }^{25}$, la superación de la comunicación meramente "formal e institucionalizada" 26 , el "sueño del orden justo"27. La realidad histórica del terrible siglo XX ha mostrado lo que puede estar detrás de estas consignas altisonantes.

\section{COMUNITARISMO VS. LIBERALISMO}

Tres factores, entre otros, han generado el actual renacimiento del comunitarismo ${ }^{28}$ : (a) la experiencia de que el mundo contemporáneo es insoportablemente complejo e insolidario, (b) la resistencia a las tendencias nivelizadoras del proceso de globalización y (c) la paulatina disolución de las identidades colectivas tradicionales y de los valores de orientación propios de cada comunidad particular. En el plano teórico ha contribuido a este renacimiento una notable crítica combinada de la democracia representativa, del mercado como instrumento universal y de los fenómenos de alienación en el mundo moderno, cuya calidad intelectual está fuera de toda duda. El liberalismo -y más claramente las variantes neoliberales -ha dejado efectivamente de lado temas relevantes hoy en el Tercer Mundo (y no sólo allí), como la identidad colectiva, la problemática de las minorías nacionales, la necesidad de reconocimiento de parte de los otros y el postulado de la redistribución equitativa de bienes e ingresos. Los enfoques hermenéuticos ${ }^{29}$ asociados al comunitarismo son, por ejemplo, escépticos con referencia a los valores universalistas del liberalismo en el plano abstracto y a tres elementos en el nivel práctico: las instituciones políticas "clásicas" provenientes de la tradición liberal, el mercado como panacea general y el derecho codificado de pretensión universalista. La positividad liminar atribuida a las instituciones, al mercado y al derecho está ahora en entredicho. Pero hay que señalar que aquello que los comunitaristas proponen en el plano del diseño institucional se destaca por su carácter nebuloso; sus apelaciones a la democracia directa no pasan de buenos deseos, desautorizados por la realidad histórica.

La gran concepción subyacente al comunitarismo (y a teorías afines) parte del contextualismo histórico, cuya fortaleza radica en observaciones de alguna precisión y en datos empíricos sólidos ${ }^{30}$. De acuerdo al contextualismo, las construcciones más esmeradas del liberalismo políticoinstitucional no provienen exclusivamente de esfuerzos abstractos racionales, sino de tradiciones históricas específicas, que distan mucho de haber sido el producto de la reflexión racional y humanista. La autorreferencialidad de las creaciones racionalistas o la generación propia de valores sociales con validez normativa racional -es decir: sin haber sido contaminados por los aspectos irracionales de la praxis-, serían mitos actuales construidos según necesidades ideológicas. La institucionalidad democrática y sus normativas se habrían desarrollado históricamente como cualquier otro sistema social ${ }^{31}$.

Estas nociones, muy populares en el Tercer Mundo por motivos obvios -la democracia sería, en última instancia, la obra de la casualidad y, por lo tanto, una creación institucional como cualquier otra -no pueden explicar la calidad intrínseca de la democracia moderna occidental, su éxito a escala mundial y su alto aprecio permanente de parte de la opinión pública esclarecida. Pero en un punto hay que considerar seriamente a los comunitaristas: esta democracia occidental, junto con todo el edificio de la modernidad, ha producido el llamado individualismo atomista y la destrucción de las formas tradicionales de solidaridad, ayuda, identidad colectiva y sentido de la historia. El liberalismo kantiano sería ahistórico, alejado de contextos reales, demasiado abstracto, insensible 
para con las situaciones específicas ${ }^{32}$. El ámbito comunitario poseería una inclinación situativa, favorable a la prudencia en situaciones concretas (phronesis), y por ello estaría más cerca de los verdaderos requerimientos de hombres concretos. El comunitarismo no concibe al Estado sólo como una gigantesca máquina bien aceitada de prestación de servicios sociales, sino también como una comunidad de destino y de historia.

Corrientes y valores particularistas, que están asociados al núcleo del comunitarismo, no pueden ser calificados sin más de irracionales y anacrónicos, como suponen los partidarios de un liberalismo racionalista doctrinario. Expresan, aunque sea de modo curioso y a menudo confuso, un malestar extendido y una crítica válida con respecto a la modernidad, a sus coerciones uniformantes y a sus resultados ocasionalmente antihumanistas. La edificación del Estado central modernizador, como se ha dado durante los últimos sesenta años en casi todo el Tercer Mundo, ha devaluado toda una gama de instituciones, normas y valores que ahora son percibidos como anticuados: los "poderes intermedios" (Alexis de Tocqueville), el ámbito de la provincia y la comarca, la solidaridad de la familia extendida y la seguridad emocional. Algunos de estos factores estaban vinculados a la religión y a las tradiciones populares, a una ética sólida $y$, más raramente, a una aceptable estética pública.

Según los comunitaristas la modernidad coloca, además, un ente abstracto, anónimo y casi siempre amenazador, como el Estado central, frente a personas inermes, aisladas y alienadas de su propia realidad. Desde los tiempos del primer romanticismo la crítica conservadora, pero clarividente $^{33}$, mostró las incongruencias de la pretensión liberal, según la cual el sujeto individual, desprovisto de contingencias y tradiciones, sería el portador de un racionalismo instrumental con intereses negociables y comprensibles para los otros. Además: tratar a toda la gente como "individuos" constituye un encubrimiento de la injusticia étnica y nacional, como lo demostraron en sus obras Will Kymlicka y otros autores ${ }^{34}$. No hay duda de que los enfoques liberales y neoliberales exhiben limitaciones en relación a los problemas de minorías étnicas (y de otros tipos) en las sociedades multiculturales del presente, máxime si los seres humanos crecen dentro de esas comunidades étnico-culturales prerracionales, donde tienen vigencia los valores tradicionales, que moldean sus pautas de comportamiento, sus principios religiosos y morales y sus aspiraciones políticas. $Y$ asimismo sus prejuicios: hay que considerar la alta probabilidad-descuidada, a su vez, por los teóricos del comunitarismo -de que las minorías de todo tipo no sólo son grupos discriminados, sino que en su estructura interior y en sus normativas prácticas están motivadas por el odio y la intolerancia y por el anhelo de ejercer el poder en detrimento de otros. Su discurso de protección contra los "intereses predominantes" encubre muchas veces sus anhelos, demasiado humanos, de convertirse en grupos predominantes y hacer lo mismo que sus adversarios.

En la constelación global hay que considerar también lo siguiente. El proceso de modernización tuvo lugar en el Tercer Mundo durante un lapso de tiempo extraordinariamente breve y ha tomado un carácter marcadamente traumático. Las naciones adelantadas trataron de acelerarlo durante la era colonial para que los países "atrasados" accedieran más rápidamente al progreso, al bienestar y a la educación popular. Los ideólogos del autoctonismo comunitario sostienen que para ello los pueblos de ultramar fueron obligados a perder su identidad específica, es decir su diferencia y distancia frente a las sociedades ya modernizadas. Según los comunitaristas, la ideología modernizante de hoy en sus versiones populares, compulsiva y dogmática como una religión secular, asevera que la imitación de lo ya alcanzado en los países metropolitanos del Norte 
es no sólo el camino obligatorio de toda evolución lograda, sino igualmente la vía más segura para liberar al Hombre de sus prejuicios, errores y supersticiones. La versión de los comunitaristas es radicalmente distinta: según ellos, los individuos del Tercer Mundo, emancipados de estos factores aparentemente negativos, se han transformado en seres desarraigados, vaciados de su identidad, desvitalizados y desesperanzados, desprovistos de proyectos originales para desarrollarse de acuerdo a sus intuiciones propias.

Desde la perspectiva racional-liberal es indispensable llamar la atención sobre la naturaleza negativa y poco idílica de la mayor parte de las creaciones de las sociedades premodernas defendidas por los comunitaristas. Sus sistemas de control social pueden ser calificados de francamente aborrecibles, su heterogeneidad no es tan amplia y colorida como la imaginan hoy los nostálgicos del pasado, su solidaridad está inmersa en ritos y costumbres detestables, su pobreza y su miseria denotan rasgos muy similares a lo ancho y a lo largo de todo el planeta y hasta sus sistemas político-institucionales exhiben un autoritarismo que permea toda la vida social. En ella no se da una movilidad apreciable de roles: el individuo es comúnmente el rol al que está predestinado desde el nacimiento, lo cual no ha sido percibido como limitante porque el rol era y es idéntico con la definición de la persona en cuestión ${ }^{35}$. La heterogeneidad de lo premoderno es rescatable en la medida en que enriquezca el panorama de las actividades humanas sin significar recaídas en comportamientos y costumbres manifiestamente bárbaras e irracionales. Lo particular, diverso y variopinto es saludable, afirman los liberales, si se respeta simultánea e inflexiblemente la vigencia de los derechos humanos y políticos y si se reconoce que la sociedad y el Estado existen, en última instancia, para el florecimiento del individuo y el despliegue de sus facultades. Finalmente hay que señalar que la solidaridad tradicional no puede ser resucitada fácilmente en un entorno moderno y complejo, donde los seres humanos no han crecido en redes de familiaridad y sociabilidad estrechas y fáciles de comprender. El sentimiento de solidaridad-como su antecesora en la Revolución Francesa: la fraternidad -puede ser manejado y desfigurado desde las instancias estatales, dando paso a comportamientos forzosos y obligados, con poco de espontaneidad y mucho de manipulación. La crónica del siglo XX ha sido particularmente rica en regímenes donde la "comunidad de destino" y la idea de un único bien común han supuesto la eliminación de las libertades individuales.

\section{ENSAYO DE SÍNTESIS}

La experiencia de que el mundo contemporáneo es insoportablemente complejo e insolidario, junto con el análisis simultáneo de los peligros inherentes al comunitarismo doctrinario, favorece intentos explicativos que combinan lo rescatable del comunitarismo y del liberalismo, como es probablemente el caso en el ensayo de una síntesis fructífera entre universalismo y particularismo. Evitando los extremos sin claudicar en la intención crítica, se puede afirmar que los derechos humanos y los estatutos morales y legales de corte universalista componen el marco dentro del cual se da una combinación de cooperación y conflicto, basada en el mutuo reconocimiento de las partes contendientes, que parece ser el modelo humano de convivencia relativamente más razonable y exitoso en la época actual y el que brinda también un mínimo de seguridad efectiva y afectiva para el florecimiento de la identidad individual, grupal y cultural ${ }^{36}$.

La organización democrático-racional de la sociedad constituye, por ejemplo, uno de esos elementos de racionalidad que traspasa las fronteras de la inmanencia contextual particularista y de la contingencia del origen de los preceptos racionales. Como afirmaron autores de la Escuela 
de Frankfurt, la argumentación racional sobrepasa el propio contexto donde ésta ha surgido y supera la llamada etnocentricidad de cada sujeto ${ }^{37}$. Una identidad personal y grupal más o menos lograda puede ser, al mismo tiempo, nacional y universal: se puede combinar, por ejemplo, una moral universalista y moderna (como los derechos humanos) con un sentimiento nacional que preserve algunos elementos particularistas. Lo que hace falta es una actitud crítica global en torno a los aspectos negativos de las tradiciones nacional-particularistas y con respecto a los lados inhumanos de la visión moderna-universalista.

Inspirándose en fragmentos de G. W. F. Hegel, sobre todo en sus escritos de juventud, Axel Honneth ha elaborado una teoría del reconocimiento que es importante para comprender en todas sus facetas la controversia entre comunitarismo y liberalismo. La formación adecuada de la identidad de un sujeto presupone el reconocimiento de parte de los otros sujetos, que puede expresarse en amor, reciprocidad y confianza, es decir en elementos esenciales para la configuración de una auto-estima, autoconfianza y un autorrespeto consolidados ${ }^{38}$. Se trata de factores y características que se dan más fácilmente en sistemas comunitarios que en modelos liberales de ordenamiento socio-político, pero que pueden ser preservadas en estos últimos mediante políticas públicas (especialmente educativas) de largo aliento.

Amar y ser amado emergen como categorías condicionantes o, por lo menos, como figuras analógicas para una participación bien lograda en la vida pública, participación que requiere de la dimensión de la solidaridad practicada y experimentada como tal. Esta última tiene algo de una reciprocidad obligada, en el sentido de una autolimitación individual por consideración a los derechos e intereses de los otros sujetos, lo que genera la primera consciencia del derecho como institución jurídica de índole racional y universalista. En el reconocimiento recíproco los sujetos se confirman mutuamente como portadores de necesidades $y$, por ende, como seres fragmentarios e imperfectos que requieren de la complementación que sólo pueden brindar los otros. Al mismo tiempo los sujetos aprender a vivir en la tensión permanente entre la afirmación individual y la entrega simbiótica al otro ${ }^{39}$. El reconocimiento se expresa en los campos del amor (oportunidad de la autoconfianza), el derecho (reconocimiento institucionalizado) y la solidaridad (la ayuda que confirma la auto-estima), y se desarrolla desde una actitud emocional hasta un respeto universalista hacia el otro, basado en un esfuerzo cognitivo de comprensión. Este complejo reconocimiento -si tiene éxito -fundamenta la autorrealización humana bien lograda ${ }^{40}$. El fenómeno negativo de la cosificación (una forma de la alienación descrita ampliamente por Hegel y Marx) se manifiesta, según Honneth, como el olvido del reconocimiento ${ }^{41}$, fenómeno que parece ser predominante en el modelo liberal.

El enfoque de Honneth se basa en la necesidad de superar la parcialidad de teorías anteriores sobre la convivencia humana ${ }^{42}$. La noción aristotélica y escolástica del Hombre como un ser básicamente apto para la sociabilidad y las teorías atomistas de Machiavelli y Hobbes en torno al conflicto y enemistad perennes del mismo, representarían visiones unilaterales de la problemática. Honneth propone una teoría sincretista -que habría sido formulada primeramente por Hegel -que retoma la vigencia intersubjetiva de normas de conducta y elementos comunicacionales -como diríamos hoy en día -contenidos en la concepción hegeliana y que "superan" el atomismo del liberalismo primigenio y la ingenuidad del humanismo clásico ${ }^{43}$. Esta síntesis parece ser hoy en día lo más razonable, no para superar el carácter insoportablemente complejo e insolidario del mundo contemporáneo, sino para mitigar sus aspectos más negativos. 


\section{NOTAS}

1 Sobre la temática del pluralismo cf. el número monográfico de DEBATS (Valencia), $\mathrm{N}^{\circ}$ 89, verano de 2005; Javier Tusell, Democracia como realidad histórica, en: ibid., pp. 52-61.

2 Sobre la temática de la identidad colectiva y sus connotaciones peligrosas, cf. el tratado exhaustivo: Lutz Niethammer, Kollektive Identität. Heimliche Quellen einer unheimlichen Konjunktur (Identidad colectiva. Fuentes secretas de una coyuntura fatídica), Reinbek: Rowohlt 2000.

3 Cf. tres textos muy instructivos: Kurt Bayertz, Begriff und Problem der Solidarität (Concepto y problema de la solidaridad), en: Kurt Bayertz (comp.), Solidarität. Begriff und Problem (Solidaridad. Concepto y problema), Frankfurt: Suhrkamp 1998, pp. 11-53; Andreas Wildt, Solidarität-Begriffsgeschichte und Definition heute (Solidaridad -historia conceptual y definición actual), en: ibid., pp. 202-216; Hauke Brunkhorst, Globale Solidarität: Inklusionsprobleme der modernen Gesellschaft (Solidaridad global: problemas de inclusión de la sociedad moderna), en: Lutz Wingert / Klaus Günther (comps.), Die Öffentlichkeit der Vernunft und die Vernunft der Öffentlichkeit. Festschrift für Jürgen Habermas (El carácter público de la razón y la razón de lo público. Homenaje a Jürgen Habermas), Frankfurt: Suhrkamp 2001, pp. 605-626.

4 Jürgen Habermas, Die postnationale Konstellation. Politische Essays (La constelación postnacional. Ensayos políticos), Frankfurt: Suhrkamp 1998, p. 95, 119 sq., 123, 133.

5 Sobre la complejidad inherente al concepto de bien común cf. el instructivo ensayo de Claus Offe, Wessen Wohl ist das Gemeinwohl? (De quién es el bien común?), en: Wingert / Günther (comps.), op. cit. (nota 3), pp. 459-488.

6 Octavio Paz, Itinerario, Barcelona: Seix Barral 1994, p. 120.

7 lbid., p. 121.

8 Giovanni Sartori, Homo videns. La sociedad teledirigida, Madrid: Santillana 1998; Jean-Marie Guéhenno, El fin de la democracia, Barcelona: Paidós 1995.

9 Octavio Paz, op. cit. (nota 6), p. 123.

10 lbid., p. 132.

11 lbid., p. 133.

12 Richard Joseph, Democracy and Prebendal Politics in Nigeria: The Rise and Fall of the Second Republic, Ibadan: Spectrum 1999, p. 57.

13 Mario Vargas Llosa, La hora de los cómicos, en: LA RAZON (La Paz) del 5 de octubre de 2003, p. A7.
14 A esta conclusión llega un gran conocedor de la temática, después de constatar que carecemos hoy de un concepto substancial de política y que estamos inundados, al mismo tiempo, por una retórica de la politización: Rüdiger Bubner, Polis und Staat. Grundlinien der Politischen Philosophie (Polis y Estado. Fundamentos de la filosofía política), Frankfurt: Suhrkamp 2002, p. 127, 192.

15 Cf. el brillante estudio de Jürgen Habermas, Vorpolitische Grundlagen des demokratischen Rechtsstaates? (Fundamentos prepolíticos del Estado democrático de Derecho?), en: Habermas, Zwischen Naturalismus und Religion. Philosophische Aufsätze (Entre naturalismo y religión. Ensayos filosóficos), Frankfurt: Suhrkamp 2005, pp. 106-118.

16 Jürgen Habermas, Kulturelle Gleichbehandlung -und die Grenzen des postmodernen Liberalismus (El tratamiento cultural igualitario -y los límites del liberalismo postmoderno), en: Habermas, Zwischen..., op. cit. (nota 15), pp. 280-283.

17 Cf. entre otros: Stefan Grätzel / Armin Kreiner, Religionsphilosophie (Filosofía de la religión), Stuttgart: Metzler 1999; Kurt Hübner, Glaube und Denken. Dimensionen der Wirklichkeit (Creencia y pensamiento. Dimensiones de la realidad), Tübingen: Mohr-Siebeck 2001.- Algunas indicaciones en torno a esta problemática en: DEBATS (Valencia), N 90, otoño de 2005 (número monográfico dedicado al paganismo).

18 Jürgen Habermas, Die Grenze zwischen Glauben und Wissen. Zur Wirkungsgeschichte und aktuellen Bedeutung von Kants Religionsphilosophie (La frontera entre fe y saber. La historia de la influencia y la importancia actual de la filosofía de la religión de Kant), en: Habermas, Zwischen..., op. cit. (nota 15), p. 234.Según Habermas, esta concepción está esbozada en: Immanuel Kant, Die Religion innerhalb der Grenzen der blossen Vernunft (La religión dentro de los límites de la razón pura) [1793], en: Kant, Werke in zehn Bänden (Obras en diez tomos), compilación de Wilhelm Weischedel, Darmstadt: WBG 1968, t. 7, p. 752 sq.

19 Jürgen Habermas, Vorpolitische..., op. cit. (nota 15), pp. 106-118.

20 Jürgen Habermas, Einleitung (Introducción), en: Habermas, Zwischen..., op. cit. (nota 15), p. 12 sq.; Habermas, Religion in der Öffentlichkeit (Religión en el ámbito público), en: ibid., p. 137, 149; Habermas, Die Grenze..., op. cit. (nota 18), p. 222.- La concepción de Ha- 
bermas está inspirada en: Immanuel Kant, Kritik der praktischen Vernunft (Crítica de la razón práctica) [1788], en: Kant, Werke, op. cit. (nota $18)$, t. 6 , p. 260.

21 Johann Baptist Metz, Anamnetische Vernunft (Razón anamnética), en: Axel Honneth et al. (comps.), Zwischenbetrachtungen. Im Prozess der Aufklärung (Observaciones interinas. En el proceso de la Ilustración), Frankfurt: Suhrkamp 1989, pp. 733, 736-738.

22 Jürgen Habermas, Vom sinnlichen Eindruck zum symbolischen Ausdruck. Philosophische Essays (De la impresión sensorial a la expresión simbólica. Ensayos filosóficos), Frankfurt: Suhrkamp 1997, pp. 100-103.- En un importante ensayo, publicado junto con un texto de Habermas, que trata de dilucidar los aspectos prepolíticos de la democracia moderna, el pontífice Benedicto XVI postuló la teoría de que los derechos humanos constituyen el puente ético de entendimiento entre los diversos actores en una sociedad secularizada y pluralista. Los derechos humanos conforman el último elemento válido del derecho natural. Los hombres se distinguen como miembros de la especie humana en cuanto son sujetos y portadores de ellos. Sus valores básicos pueden ser encontrados, pero no pueden ser inventados arbitrariamente. Cf. Joseph Ratzinger, Was die Welt zusammenhält. Vorpolitische moralische Grundlagen eines freiheitlichen Staates (Lo que mantiene unido al mundo. Fundamentos morales prepolíticos de un Estado liberal), en: Jürgen Habermas / Joseph Ratzinger, Dialektik der Säkularisierung. Über Vernunft und Religion (Dialéctica de la secularización. Sobre razón y religión), Freiburg etc.: Herder 2005, p. 50 sq.

23 Cf. Ernesto Laclau, La razón populista, Buenos Aires: FCE 2005; Ernesto Laclau / Chantal Mouffe, Hegemonía y estrategia socialista. Hacia una radicalización de la democracia, Madrid: Siglo XXI 1987; Chantal Mouffe (comp.), Deconstrucción y pragmatismo, Buenos Aires: Paidós 1998; Enrique Dussel, Introducción a la Filosofía de la Liberación, Bogotá: Nueva América 1998; Dussel, Etica de la liberación, México: UNAM / Trotta 1998; Francisco Naishtat, Acción colectiva y regeneración democrática del espacio público, en: Hugo Quiroga / Susana Villavicencio / Patrice Vermeren (comps.), Filosofías de la ciudadanía. Sujeto político y democracia, Rosario: Homo sapiens 2001, pp. 69-88; Jacques Rancière, El desacuerdo, Buenos Aires: Nueva Visión 1998; Jacques Rancière, La politique de la sirène, París:
Hachette 1996; Hugo Quiroga, La democracia que tenemos. Ensayos políticos sobre la Argentina actual, Rosario: Homo sapiens 1995.

$24 \mathrm{Y}$ hasta una celebración de la guerriIla guevarista. Cf. Miguel Benasayag / Diego Sztulwarkal, Du contre-pouvoir, París: La Découverte 2000; Miguel Benasayag, Che Guevara: du mythe à I'homme. Aller-retour, París: Bayard 2003; Miguel Benasayag / Angélique del Rey, Éloge du conflit, París: La Découverte 2007.

25 Sobre la complejidad del principio de igualdad y sus nexos con la justicia, cf. Wolfgang Kersting, Kritik der Gleichheit. Über die Grenzen der Gerechtigkeit und der Moral (Crítica de la igualdad. Sobre los límites de la justicia y la moral), Weilerswist: Velbrück 2005; Stefan Gosepath, Über den Zusammenhang von Gerechtigkeit und Gleichheit (Sobre la relación entre justicia e igualdad), en: Wingert / Günther (comps.), op. cit. (nota 3), pp. 403-433.

26 La "acción colectiva" como "respuesta de índole metacomunicativa e informal a una disrupción de la comunicación formal e institucionalizada": Francisco Naishtat, op. cit. (nota 23), p. 72.

27 Hugo Quiroga, Democracia, ciudadanía y el sueño del orden justo, en: Quiroga / Villavivencio / Vermeren (comps.), op. cit. (nota 23), pp. 187-207. El autor afirma que una sociedad democrática no puede convivir con "desigualdes insoportables", aunque admite que es muy difícil determinar cuál es el grado de desigualdad todavía soportable en democracia (ibid., p. 193 sq.).

28 Armin Pfahl-Traughber, "Gemeinwohl" versus Freiheit. Zur Auseinandersetzung zwischen Kommunitarismus und Liberalismus ("Bien común" vs. libertad. Sobre el debate entre comunitarismo y liberalismo), en: LIBERAL. VIERTELJAHRESHEFTE FÜR POLITIK UND KULTUR (Bonn), vol. 43, N 1, marzo de 2001, pp. 16-20.

29 Sobre las teorías comunitaristas cf. el brillante ensayo de Wolfgang Kersting, Theoriekonzeptionen der politischen Philosophie der Gegenwart: Methoden, Probleme, Grenzen (Concepciones teóricas de la filosofía política del presente: métodos, problemas, límites), en: Michael Th. Greven / Rainer Schmalz-Bruns (comps.), Politische Theorie-heute. Ansätze und Perspektiven (Teoría política -hoy. Enfoques y perspectivas), Baden-Baden: Nomos 1999, pp. 41-79, especialmente pp. 71-76.

30 Cf. las obras clásicas: Marc Augé, Hacia una antropología de los mundos contemporá-

RIPS, ISSN 1577-239X. Vol. 7, núm. 2, 2008, 9-23 
neos, Barcelona: Gedisa 1996; Charles Taylor, EI multiculturalismo y la política del reconocimiento, México: FCE 1993; Axel Honneth (comp.), Kommunitarismus. Eine Debatte über die moralischen Grundlagen moderner Gesellschaften (Comunitarismo. Un debate sobre los fundamentos morales de las sociedades modernas), Frankfurt / New York: Campus 1993; y el número monográfico de ISEGORIA (Madrid), N 14, octubre de 1996.

31 Cf. Werner Becker, Die Überlegenheit der Demokratie. Politische Philosophie nach dem Scheitern des Marxismus (La supremacía de la democracia. Filosofía política después del fracaso del marxismo), en: Kurt Bayertz (comp.), Politik und Ethik (Política y ética), Stuttgart: Reclam 1996, pp. 40-62, especialmente pp. 55-57.

32 Cf. el excelente ensayo de Kurt Bayertz, Staat und Solidarität (Estado y solidaridad), en: Kurt Bayertz (comp.), op. cit. (nota 31), pp. 305329.

33 Michael Oakeshott, El racionalismo en política y otros ensayos, México: FCE 2000.

34 Will Kymlicka, Derechos individuales y derechos de grupo en la democracia liberal, en: ISEGORIA (Madrid), No 14, octubre de 1996, p. 35 sq.; Will Kymlicka, Ciudadanía multicultural, Barcelona: Paidós 1996; Renato Ortiz, Diversidad cultural y cosmopolitismo, en: NUEVA SOCIEDAD (Caracas), № 155, mayo-junio de 1998, pp. 23-36.

35 Cf. el excelente estudio de Patricia Crone, Pre-industrial Societies, Oxford: Blackwell 1989 , p. 132 sq.

36 Cf. Nodari A. Simonia, Synthesis of Traditional and Modern in the Evolution of Third World Societies, New York: Greenwood 1992, passim.
37 Albrecht Wellmer, Endspiele: die unversöhnliche Moderne (Juegos finales: la modernidad irreconciliada), Frankfurt: Suhrkamp 1993, p. 54 sq., 172 sq.; Jürgen Habermas, Die Einheit der Vernunft in der Vielfalt ihrer Stimmen (La unidad de la razón en la diversidad de sus voces), en: Habermas, Nachmetaphysisches Denken (Pensamiento postmetafísico), Frankfurt: Suhrkamp 1988, p. 174 sqq.- Para una crítica diferenciada y sugerente de la posición de Habermas, cf. Jorge Larraín Ibáñez, Modernidad, razón e identidad en América Latina, Santiago de Chile: Andrés Bello 1996, p. 221 sq.

38 Axel Honneth, Kampf um Anerkennung. Zur moralischen Grammatik sozialer Konflikte (La lucha por el reconocimiento. Sobre la gramática moral de los conflictos sociales), Frankfurt: Suhrkamp 1994, p. 64 sq., 128, 153 sq., 172.

39 lbid., p. 65 sq., 68, 73, 153 sq.

40 lbid., pp. 151-154, 175-178, 278 sq.

41 Axel Honneth, Verdinglichung. Eine anerkennungstheoretische Studie (Cosificación. Un estudio en la teoría del reconocimiento), Frankfurt: Suhrkamp 2005, pp. 62-77.

42 Honneth, Kampf..., op. cit. (nota 38), pp. 13-18, 21-26, 32, 110, 267.

43 Sobre el enfoque de Axel Honneth, que se reclama del realismo hegeliano, es indispensable indicar también lo siguiente. Esta teoría exhibe rasgos tan abstractos y generales, que recae en el idealismo que critica. Las grandes obras de la literatura, que examinan los conflictos morales de individuos concretos en situaciones específicas, contribuyen de manera más clara y adecuada a comprender los problemas reales que emanan de la carencia de reconocimiento y reciprocidad. 